\title{
Exposing Seeds of Galtonia candicans to Ethyl Methanesulfonate Reduced Inflorescence Height, Lodging, and Fertility
}

\author{
Ryan N. Contreras \\ Department of Horticulture, Oregon State University, 4017 Agricultural and \\ Life Sciences, Corvallis, OR 97331
}

\author{
Kim Shearer \\ The Morton Arboretum, 4100 Illinois Route 53, Lisle, IL 60532
}

Additional index words. cape hyacinth, chemical mutagens, Hyacinthaceae, mutagenesis, sterility

\begin{abstract}
Cape hyacinth (Galtonia candicans) is a geophytic herbaceous perennial from South Africa. It produces large inflorescences of pendulous white flowers during mid to late summer, followed by capsules filled with copious amounts of seed. The species has potential as a low-water-use landscape plant, but lodging and excessive seed production, which pose a risk of escape or invasion, are issues that should be addressed before marketing. Ethyl methanesulfonate (EMS) is a chemical mutagen known to induce usable mutations including dwarfing and sterility. We exposed seeds of cape hyacinth to increasing concentrations of EMS $(0 \%, 0.2 \%, 0.4 \%, 0.6 \%, 0.8 \%$, and $1 \%)$. Increased concentrations of EMS resulted in a linear decrease in seed germination when not exposed to a presoak treatment in water before exposure to EMS. No seedlings survived or were viable to field plant at $0.6 \%, 0.8 \%$, or $1 \%$. Resulting plants were field planted in 2013 and evaluated during 2014 and 2015. In both years, the inflorescence height at first flower, average seed number per capsule, and percent lodging were reduced in EMStreated plants compared with controls. In 2015, pollen staining was evaluated and was reduced from $83 \%$ in control to less than $3 \%$ in the $0.4 \%$ treatment. Our study demonstrated that EMS is a viable option to reduce height and decrease seed set in cape hyacinth.
\end{abstract}

Galtonia candicans (syn. Ornithogalum candicans), cape hyacinth, is an herbaceous perennial geophyte native to elevations of 1350 to $2150 \mathrm{~m}$ in the Drakensberg region of the Great Escarpment in South Africa (Hilliard and Burtt, 1988). It is naturally self-pollinating and can be clonally propagated by bulb division or twin-scaling. White flowers are borne on racemes that emerge from a crown of strap-like foliage from $\mathrm{Au}$ gust to September in the Northern Hemisphere (Armitage, 2008). Inflorescences of $G$. candicans can grow up to $1.2 \mathrm{~m}$, which

Received for publication 4 Dec. 2019. Accepted for publication 13 Jan. 2020.

Published online 3 April 2020.

We gratefully acknowledge Mara Friddle for technical assistance in growing containerized and field plants. Funding, in part, was provided through a cooperation between the Oregon Department of Agriculture (ODA) Nursery Research and Regulatory Advisory Committee and the Oregon Association of Nurseries (OAN). Financial support is provided through a research assessment included as part of ODA's annual nursery license fee.

R.N.C. is the corresponding author. E-mail: ryan. contreras@oregonstate.edu.

This is an open access article distributed under the CC BY-NC-ND license (https://creativecommons. org/licenses/by-nc-nd/4.0/). can result in lodging due to the length of the peduncle and lack of sufficient support (personal observation). Cape hyacinth has been shown to be hardy for gardens of North America (Armitage, 2008) but there has been little cultivar development. The only cultivar that has been described is the doubleflowered Moonbeam, discovered in a New Zealand garden in 1982 (Hammett and Murray, 1993). The species shows promise as a low-input option for landscapes due to its pest resistance and low water use, but its issue with lodging requires improvement. However, there is a narrow genetic base, and we are unaware of sources of diversity with which to breed.

Mutagenesis is a common method used by plant breeders to induce genetic variation in plants and can be particularly useful for naturally self-pollinating plants (Waugh et al., 2006). EMS is a preferred method due to ease of access, its chemical mode of action, and cost compared with methods such as exposure to radiation. EMS treatments result in point mutations in plants by attaching an ethyl group to the oxygen atom of guanine. The direct result of this mutation is the transition from a $\mathrm{G} / \mathrm{C}$ pairing to an $\mathrm{A} / \mathrm{T}$ pairing in the genome (Waugh et al., 2006). Prior studies have demonstrated varying effects on germination and survival rates rela- tive to varying concentrations of EMS treatment, as well as changes in seed dormancy (Greer and Rinehart, 2009; Hoskins and Contreras, 2019; Talebi et al., 2012).

Weigle and Butler (1983) reported hereditary dwarfing effects after EMS treatment of Impatiens platypeta seeds and in Capsicum annuum, Jabeen and Mirza (2004) demonstrated that EMS was effective in inducing dwarf mutations and sterility. These results, if observed in cape hyacinth, would result in improved cultivars with potential as containerized summer-flowering perennials for retail sales, reduced lodging to improve landscape performance, and reduced fertility to prevent escape from cultivation. The objective of this study was to evaluate the effects of increasing concentrations of EMS on G. candicans for these traits.

\section{Materials and Methods}

Mutagenesis and germination. In 2011, seed from landscape plants of $G$. candicans at Oregon State University North Willamette Research and Extension Center (Aurora, OR) were collected. An experiment was conducted following a completely randomized design with a factorial arrangement of treatments. Treatments originally consisted of two factors, a presoak factor (presoak in water vs. no presoak in water) and an EMS concentration factor $(0 \%$ control, $0.2 \%$, $0.4 \%, 0.6 \%, 0.8 \%, 1.0 \%$ ). However, following poor seed germination in the presoak treatment, subsequent tests did not include this treatment. A $t$ test was conducted to compare percent seed germination of presoak and no presoak groups within each EMS concentration with no comparison among EMS concentrations. We used the Satterthwaite method $(\mathrm{df}=32.7)$ due to unequal variances $(F=1.49 ; P=0.42)$. Each treatment (two soak treatments $\times$ six concentrations of EMS) was replicated three times for a total of 36 experimental units, each of which consisted of lots of 300 seeds. In the presoak treatment, seeds were soaked in water with one drop of Tween 20 for $24 \mathrm{~h}$ before EMS treatment. EMS treatments, including control, were applied as a 24-h soak by diluting EMS in a $0.1 \mathrm{M}$ phosphate buffer. For all soaks, seeds were incubated in a 0.5 -L flask placed on a rotary shaker at $100 \mathrm{rpm}$. After treatments, seed lots (experimental units) were rinsed under running tap water for $15 \mathrm{~min}$ and sown in separate 0.2 -L containers filled with soilless media (Metro-Mix 350; Sungro Horticulture Canada Ltd., Agawam, MA) for germination in a glasshouse with day/night set temperatures of $22 / 16^{\circ} \mathrm{C}$. Due to extensive mortality in the presoak treatment, regression was used to assess the relationship between \% EMS in the presoak and no-soak treatments separately. In the presoak group, we fit an exponential curve using PROC NLIN (SAS 9.4; SAS Institute Inc., Cary, NC) and used linear regression for the no-soak treatment in a spreadsheet (Excel; Microsoft, Redmond, WA).

Growing and field planting of $M_{1}$ plants. In Feb. 2012, germinated seedlings were 
transplanted to 0.37 -L square polypropylene pots (Kord, Canada) filled with douglas firbased soilless substrate and grown in an unheated poly-house at the OSU LewisBrown Farm. In Oct. 2012, plants were placed in a dark $4{ }^{\circ} \mathrm{C}$ cooler for a $90-\mathrm{d}$ vernalization treatment. After the vernalization treatment, the plants were moved into a glasshouse with day/night set temperatures of

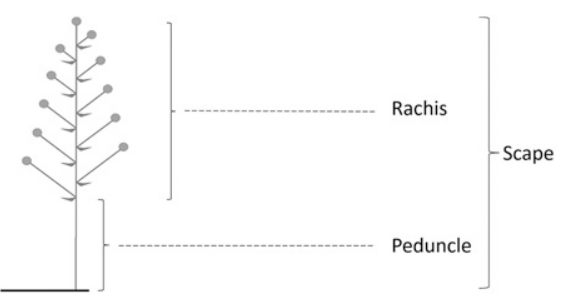

Fig. 1. Schematic of Galtonia candicans inflorescence.
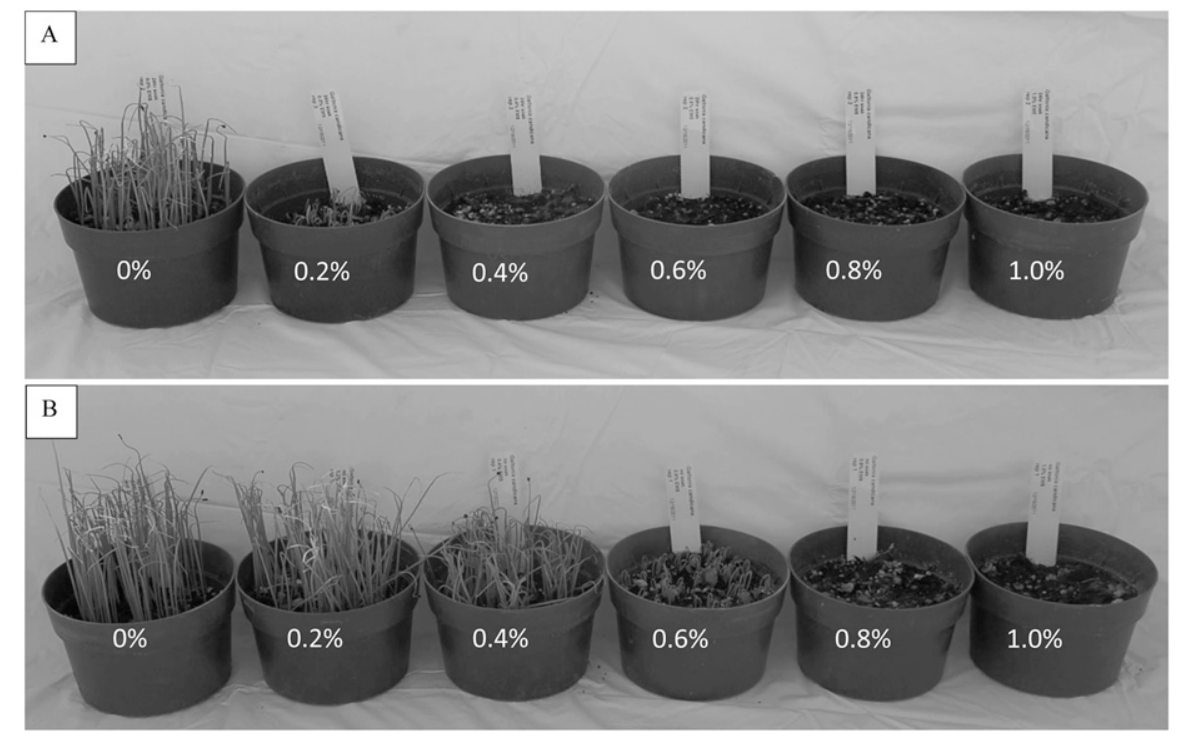

Fig. 2. Germination of Galtonia candicans seedlings 10 weeks after treating seed in $0 \%, 0.2 \%, 0.4 \%, 0.6 \%$, $0.8 \%$, or $1.0 \%$ EMS for $24 \mathrm{~h}$ following a $24-\mathrm{h}$ pretreatment in water $(\mathbf{A})$ or no pretreatment $(\mathbf{B})$.

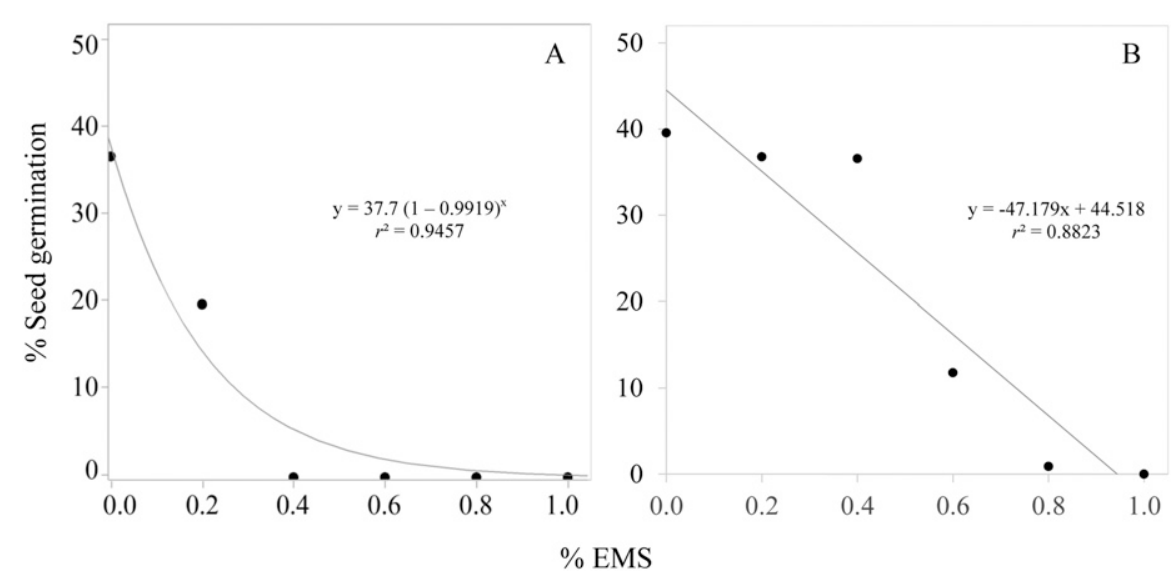

Fig. 3. Galtonia candicans seed germination decreased in response to increasing ethyl methanesulfonate (EMS) concentration. (A) There was an exponential response when seeds were exposed to a 24-h soak in water before application of EMS treatments and (B) a linear response without soaking before EMS treatment. Median lethal dose $\left(\mathrm{LD}_{50}\right)$ for seed with the presoak in water was $0.15 \%$ and without presoak treatment was $0.52 \%$ EMS. and average seed set per capsule. Qualitative data analyzed was for lodging (yes $=1$ or no $=$ 0 ). The number of plants (observations) was not consistent from planting and was primarily due to plant mortality, but there also were plants that did not flower in 2014 yet flowered in 2015. In 2014, the following number of plants were evaluated in each treatment: 121 in $0 \%$ ( -39 from planting), 154 in $0.2 \%(-105$ from planting), and 43 in $0.4 \%$ (-104 from planting). In 2015, the following number of plants were evaluated in each treatment: 122 observations in $0 \%$ ( -38 from planting and +1 from 2014), 164 in $0.2 \%$ (-95 from planting and +10 from 2014), and 41 in $0.4 \%$ ( -106 from planting and -2 from 2014).

Pollen staining. Flowers were collected from randomly selected $\mathrm{M}_{1}$ plants (25 control, $260.2 \%, 190.4 \%$ ) in the field for a pollen-staining test as an estimate of viability. Pollen was wet mounted using a drop of $1 \%$ acetocarmine. For each rep and treatment in the field, the pollen of 5 to 12 flowers was analyzed using one slide per flower. For each slide, 100 pollen grains were counted and scored as stained or unstained. Pollen grains were scored as stained if stain was taken up into the pollen grain and scored as unstained if less than $25 \%$ of the pollen grain was stained.

Data analysis. For field evaluation and pollen staining analysis of variance was conducted using a general linear model (PROC GLM using SAS 9.4) to determine whether treatment (EMS\%) and/or replicate had a significant impact on response variables (scape height, average seed set per capsule, percent lodging, and pollen staining). All response variables were evaluated for normality (PROC UNIVARIATE; SAS 9.4). Scatterplot, best fit curves, regression equations, and multiple correlation coefficients $\left(r^{2}\right)$ were prepared in Excel (Microsoft Corporation, Redmond, WA) to visualize relationships between independent and response variables.

\section{Results and Discussion}

$M_{1}$ germination. The 24-h presoak in water before EMS treatment reduced seed germination $(t=2.12 ; \mathrm{df}=32.7 ; P=0.0418$; Figs. 2 and 3). Also, percent seed germination decreased as EMS concentration increased in both presoak and non-presoaked treatments (Fig. 3). The relationship in the presoak was exponential and there was $100 \%$ mortality at $0.4 \%$ EMS and higher concentrations in the presoak treatment (Fig. 3A), whereas there was a linear decrease in germination with increasing EMS in the no-soak treatment (Fig. 3B). Given the high mortality and poor survival of seeds exposed to presoak treatment, we recommend exposing seeds directly to EMS treatment. Alternatively, if a presoak treatment is imposed, a shorter EMS treatment or lower concentration may yield better results (increased survival) than we observed. The median lethal dose $\left(\mathrm{LD}_{50}\right)$ for seed with the presoak in water was $0.15 \%$ and without presoak treatment was $0.52 \%$ EMS. 
An observation made during the study was that the extremely dense sowing in the experiment may have reduced germination due to competition. To explore this, we conducted a separate, somewhat informal study during 2015 to assess the impact of sowing density on germination of untreated seeds. The initial average germination of control seeds in 2011 was $37 \%$, while the average germination of control seeds in the germination study conducted during 2015 was $89 \%$. This is may be due to the higher density of seed sown during the 2011 experiment. There were 300 seed sown per experimental unit in 2011 , and just 30 seeds sown per experimental unit in 2015. The containers used in both experiments were the same size $(0.2 \mathrm{~L})$ but with 10 times the number of seeds in the first study. Germination percent observed through a second germination experiment conducted in 2016 was consistent with the results of the 2015 experiment, indicating that germination across all treatments may have been higher with lower sowing density.

Density of seed sown has been demonstrated to inhibit seed germination due to resource competition (Inouye, 1980). In $G$. candicans, there was a difference in germination timing, with some seeds germinating weeks before others in the same container. This may have put later-germinating seeds at a competitive disadvantage for water or nutrients. Additionally, the media in which seeds were sown for the initial EMS experiment was bark medium that had been stored outdoors without any protection or sterilization. It is possible that the medium was contaminated by pathogens. In another germination project in the same year, Pythium was identified as a contaminant in the bark medium causing damping off. Future studies on cape hyacinth or any other taxa should limit the number of seeds per container to prevent competition and use a sterile soilless substrate.

Scape height at first flower decreased with increasing EMS concentration (Fig. 4; Table 1) during both $2014(\mathrm{df}=2 ; F=96.0 ; P<$ 0.0001 ) from $89 \mathrm{~cm}$ in control to $61 \mathrm{~cm}$ in $0.4 \%$ and during 2015 (df $=2 ; F=69.1 ; P<$ 0.0001 ) from $94 \mathrm{~cm}$ in control to $61 \mathrm{~cm}$ in $0.4 \%$. Height was normally distributed in both years, and rep effect was not significant. Scape height at first flower was evaluated due to the selection criterion for this project-reduced scape height for containerized flowering perennial. On the basis of field observations, a number of genotypes with reduced height also produced many inflorescences throughout the summer into early fall.

Seed set per capsule of $M_{1}$ plants was significantly reduced with increasing EMS concentration. Control plants had an average of 17.4 in 2014 and 11.9 in $2015,0.2 \%$ plants had 2.8 in 2014, and 0.93 in 2015, and $0.4 \%$ plants had 0.014 in 2014 and 0 in 2015 (Table 1; Fig. 4). Seed germination also reduced as EMS concentration increased (data not shown), although full replicated experiments were not conducted.

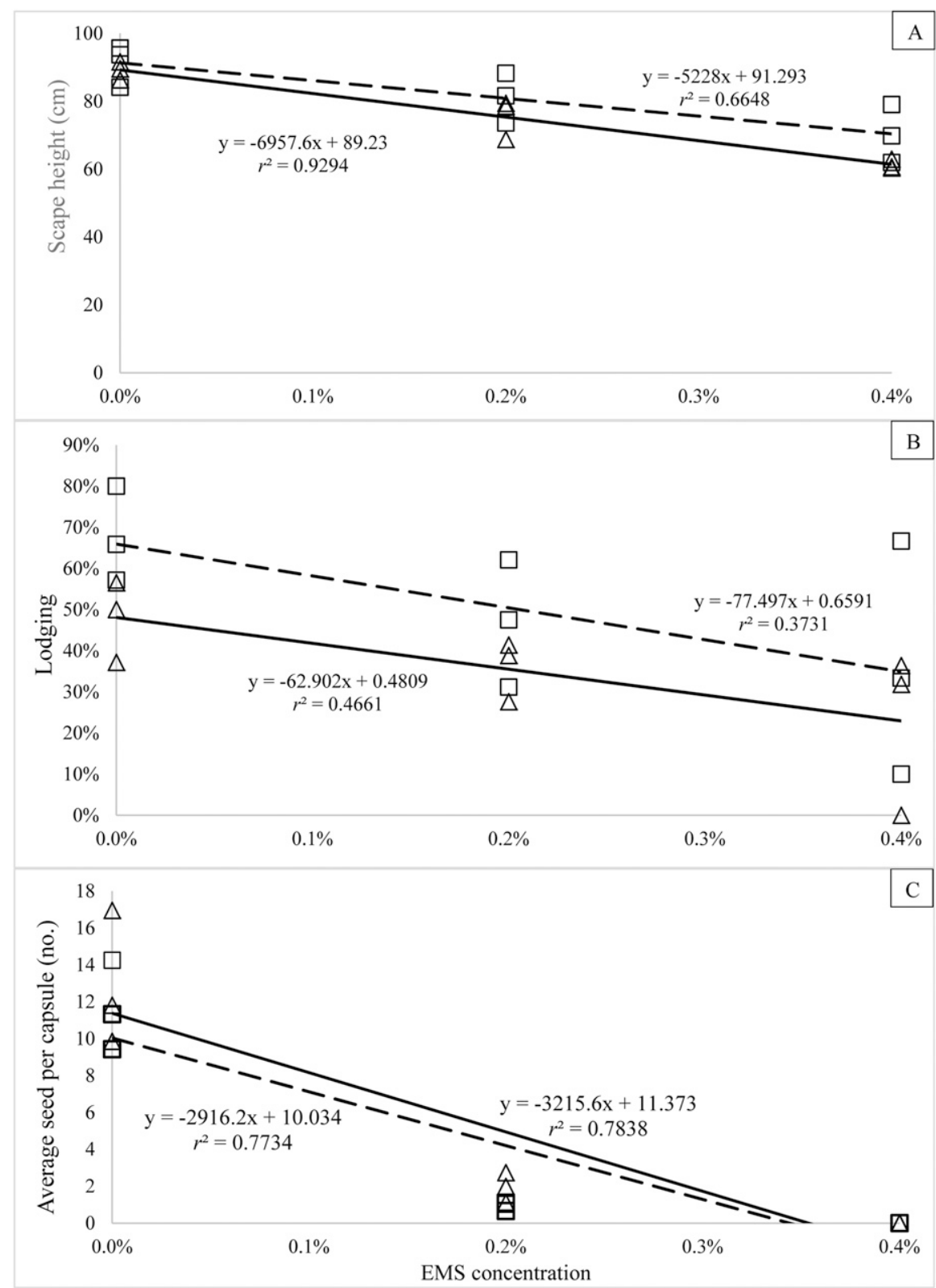

Fig. 4. Increasing ethyl methanesulfonate (EMS) concentration reduced (A) scape height, (B) lodging, and (C) average seed per capsule in Galtonia candicans during $2014(\Delta)$ and $2015(\square)$. Data points represent the mean of each replicate $(n=3)$.

Table 1. Decreasing scape height at first flower, average seed set per capsule, and pollen viability with increasing \% ethyl methanesulfontate (EMS) treatment of Galtonia candicans. Observations were collected from $\mathrm{M}_{1}$ field grown plants in Corvallis, OR, and observed during 2014 and 2015. Analysis of variance performed using PROC GLM and means separated using Tukey's honestly significant difference ( $\mathrm{n}=3 ; \alpha=0.05)$ in SAS 9.4. Years (2014 and 2015) were analyzed separately with no statistical comparisons made between years.

\begin{tabular}{|c|c|c|c|c|}
\hline EMS & $\begin{array}{l}\text { Scape ht } \\
(\mathrm{cm})\end{array}$ & $\begin{array}{l}\text { Avg no. seed } \\
\text { per capsule }\end{array}$ & Lodging (\%) & $\begin{array}{c}\text { Pollen } \\
\text { stainability }(\%)\end{array}$ \\
\hline \multicolumn{5}{|c|}{2014} \\
\hline $0 \%$ & $89.2 \mathrm{a}^{\mathrm{z}}$ & $17.4 \mathrm{a}$ & $53.8 \mathrm{a}$ & - \\
\hline $0.2 \%$ & $77.2 \mathrm{~b}$ & $2.78 \mathrm{~b}$ & $40.8 \mathrm{ab}$ & - \\
\hline $0.4 \%$ & $61.1 \mathrm{c}$ & $0.014 \mathrm{c}$ & $27.5 \mathrm{~b}$ & - \\
\hline \multicolumn{5}{|c|}{2015} \\
\hline $0 \%$ & $94.2 \mathrm{a}$ & $11.9 \mathrm{a}$ & $68.9 \mathrm{a}$ & $82.9 \mathrm{a}$ \\
\hline $0.2 \%$ & $80.1 \mathrm{~b}$ & $0.929 \mathrm{~b}$ & $46.6 \mathrm{~b}$ & $21.1 \mathrm{~b}$ \\
\hline $0.4 \%$ & $61.0 \mathrm{c}$ & $0 \mathrm{~b}$ & $32.3 \mathrm{~b}$ & $2.76 \mathrm{c}$ \\
\hline
\end{tabular}

${ }^{\mathrm{z}}$ Means within columns, within year, followed by different letters are significantly different based on Tukey's honestly significant difference $\alpha=0.0$. 
Pollen viability, using pollen staining as a proxy, was evaluated during Summer 2015, to determine whether perhaps sufficient viable pollen contributed to reduced seed set (observed female fertility). The uptake of $1 \%$ acetocarmine by pollen is significantly reduced with increasing EMS concentration suggesting decreased viability. Control pollen stained $83 \%, 0.2 \%$ EMS pollen stained $21 \%$, and the $0.4 \%$ EMS pollen stained $3 \%$. Although this is a potential source of selfinfertility, there is still the potential of crosspollination through pollinator visitations. Many pollinators were observed in the field, including flies, bees, and hummingbirds. This could explain the seed found on a $0.4 \%$ EMS plant when no viable pollen was observed in samples taken from these plants.

Lodging was reduced from $54 \%$ in control plants to $28 \%$ in $0.4 \%$ plants during 2014 , and from $69 \%$ in control plants to $32 \%$ in $0.4 \%$ plants during 2015 (Table 1; Fig. 4). Lodging data were nonnormal based on the Shapiro-Wilk test $(W=0.6225 ; P<0.0001)$, but due to the robust nature of using the general linear model and our observed biological significance of differences, we accepted that treatment significantly reduced lodging during $2014(P=0.0188)$ and 2015 $(P<0.0001)$. However, although there was lodging observed in the $\mathrm{M}_{1}$ field, there were no such observations of controls in the M2 field. The difference in planting depth most likely contributed to this. Bulblets planted in the $\mathrm{M}_{1}$ field were planted at a depth of $\approx 5 \mathrm{~cm}$ compared with planting depth of $\mathrm{M}_{2}$ plants at $20 \mathrm{~cm}$. We planted the second generation deeper due to noted observations on the exposure of bulb crowns in the shallowly planted field. Other cultural practices to consider are growing conditions of seedlings. Seedlings of the $\mathrm{M}_{1}$ generation were grown in relatively shallow containers, whereas $\mathrm{M}_{2}$ seedlings were transplanted to tubes to provide space for root growth. Although these observations may have contributed to reduced lodging among all treatments in the $\mathrm{M}_{2}$ population (data not shown), increasing EMS appeared to reduce lodging in the $M_{1}$ population. Furthermore, cape hyacinth has been observed to exhibit extensive lodging in other landscape situations where bulbs were larger and planted deeper (personal observation). Reduced lodging might be related to both the height and thickness of the scape. However, although we did observe variation among genotypes for scape thickness, there were not obvious differences between $M_{1}$ and $\mathrm{M}_{2}$ populations to account for the reduced lodging in the latter.

\section{Conclusion}

Treating seeds of cape hyacinth with EMS was an effective method of decreasing height and simultaneously reducing lodging. These related traits were improved along with a reduction in seed production with increasing concentration of EMS. Modern landscapes increasingly require plants that are compact to fit into shrinking planting areas. Furthermore, greater attention is given to ornamental plants that escape cultivation and reduced seed production/fertility can be viewed as a value-added trait. Cape hyacinth has inherent low water use and long, late-season flowering time. This, combined with more compact and seedless selections, may make $G$. candicans a viable option for perennial markets. EMS mutagenesis was again proven to be a useful tool that may be applied to other landscape crops.

\section{Literature Cited}

Armitage, A.M. 2008. Herbaceous perennial plants: A treatise on their identification, culture, and garden attributes. 3rd ed. Stipes Publishing, Champaign, IL.

Greer, S.P. and T.A. Rinehart. 2009. In vitro germination and dormancy responses of Hydrangea macrophylla and Hydrangea paniculata seeds to ethyl methane sulfonate and cold treatment. HortScience 44:764-769.

Hammett, K.R.W. and B.G. Murray. 1993. On the polyploidy origin of Galtonia 'Moonbeam'. N. Z. J. Crop Hort. Sci. 21:279-281.

Hilliard, O.M. and B.L. Burtt. 1988. A revision of Galtonia (Liliaceae). Notes R. Bot. Gard. Edinb. 45:95-104.

Hoskins, T. and R.N. Contreras. 2019. Exposing seeds of Sarcococca confusa to increased concentration and duration of ethyl methanesulfonate reduced seed germination, twinning, and plant size. HortScience 54:1902-1906.

Inouye, R.S. 1980. Density-dependent germination response by seeds of desert annuals. Oecologia 46:235-238.

Jabeen, N. and B. Mirza. 2004. Ethyl methane sulfonate induces morphological mutations in Capsicum annuиm. Intl. J. Agr. Biol. 6:340-345.

Talebi, A.B., A.B. Talebi, and B. Shahrokhifar. 2012. Ethyl methane sulphonate (EMS) induced mutagenesis in Malaysian rice (cv. MR219) for lethal dose determination. Amer. J. Plant Sci. 3:1661-1665.

Waugh, R., D.J. Leader, N. McCallum, and D. Caldwell. 2006. Harvesting the potential of induced biological diversity. Trends Plant Sci. 11:71-79.

Weigle, J.L. and J.K. Butler. 1983. Induced dwarf mutant in Impatiens platypetala. J. Hered. 74:200. 